\title{
A gene suppressing the allelic protoplasmic incompatibility specified by genes at five different loci in Podospora anserina
}

\author{
JEAN BERNET* \\ Laboratoire de Génétique, Université de Bordeaux II, Avenue des Facultés, 33405 Talence, France
}

(Received 21 May 1992; revised 3 August 1992; accepted 25 August 1992)

\begin{abstract}
Protoplasmic incompatibility (PI) in fungi is a phenomenon of immediate cell destruction resulting from the fusion of cells of unlike genotypes. In Podospora anserina, five loci contain genes determining PI as the result of allelic gene interactions. The present work shows that mutations of a gene called modD inhibit allelic PI irrespective of the locus responsible for the phenomenon. Other modD mutations show differential actions on the allelic interactions and on the expression of the two allelic incompatibility genes of the same locus. These results thus suggest that the modD gene product is involved in the trigger mechanism of allelic PI. The modD gene acts in differentiation: it has been previously shown to control proteolytic activities required for exit from stationary phase. There is thus a connection between this function and allelic PI. This leads to the suggestion that allelic incompatibility genes are involved in the control of stationary phase exit to promote differentiation.
\end{abstract}

\section{Introduction}

Protoplasmic incompatibility (PI) in fungi manifests itself as a process of cell destruction that immediately follows the fusion of hyphae of unlike genotypes (Garnjobst \& Wilson, 1956). In Neurospora crassa, PI results from the interaction of the allelic genes of about ten identified loci, including that of the mating type (Mylyk, 1976; Perkins et al., 1982). In Podospora anserina, PI was first described using the term 'barrage' due to a secondary effect of PI: the production of an unpigmented mycelial excrescence on the confluence area of mycelia cultured on solid media (Rizet, 1953; Rizet \& Esser, 1953; Bernet, 1965). Five loci for allelic incompatibility and nine for non-allelic incompatibility have been identified in P. anserina (Fig. 1).

Several hypotheses have been proposed to explain the biological significance of PI and to account for its widespread occurrence in fungi. Due to its action on vegetative cells, PI has been interpreted as a mechanism protecting individual mycelial clones against cytoplasmic infections (Caten, 1972) or preventing exploitation of heterokaryons by nuclei that are non-adaptative in homokaryons (Hartl et al., 1975). In $P$. anserina, protoperithecia and microconidia can display PI in their interaction and this leads to a general reduction of the

Abbreviation: PI, protoplasmic incompatibility. interfertility between wild-type isolates (Bernet, 1965, 1967). PI has hence been interpreted as a breeding system limiting the outbreeding supposed to result from the action of the mating type locus (Esser, 1971).

The selection, in this laboratory, of mutations inhibiting non-allelic PI has led to a radically different hypothesis. Genetic studies showed that the mutation of two genes $(\bmod A$ and $\bmod B)$ is required to suppress PI, irrespective of the non-allelic gene interaction $(C / D, C / E$ $\ldots$ or $R / V$ ) responsible for the phenomenon (Boucherie \& Bernet, 1974). modA modB mutants do not produce aerial organs (protoperithecia and aerial hyphae), due to the action of the mutations on vegetative cells (Boucherie \& Bernet, 1980). Cell death in fungi is a process of cell destruction associated with the development of aerial organs, especially proto- and perithecia. Work with $P$. anserina suggested that cell death is a requirement for the development of aerial organs by mycelium and is controlled by the $\bmod A$ and $\bmod B$ genes (Bernet, 1991). The action of $\bmod A \bmod B$ mutations therefore established a connection between non-allelic PI and cell death. Accordingly, it was suggested that non-allelic PI results from the dysregulation (as a consequence of mutations in the $c$ to $v$ non-allelic incompatibility genes leading to the $C / D \ldots$ to $R / V$ lethal interactions) of degradative activities (especially proteases) that are developmentally controlled so as to transform stationaryphase cells into a source of nutrients for developing fruiting bodies (Bernet, 1992). 


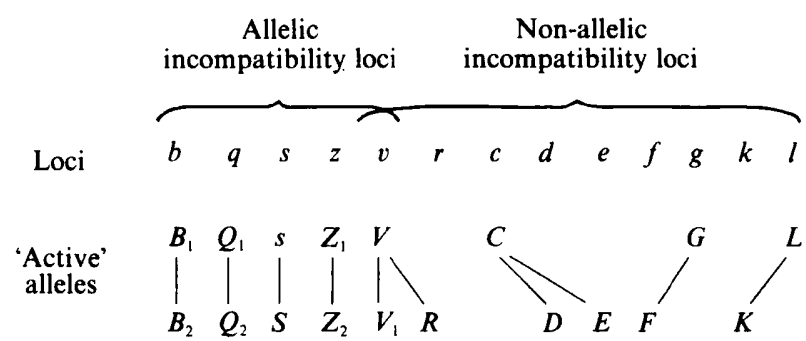

Fig. 1. Allelic and non-allelic incompatibility genes in $P$. anserina. The five allelic loci $(b, q, s, z$ and $v)$ and five of the nonallelic incompatible loci ( $c, d, e, r$ and again the $v$ locus) come from the study of 16 wild-type strains (Bernet, 1965, 1967). Non-allelic incompatibility loci $f, g, k$ and $l$ were identified following the selection of induced mutations in the reference strain (Delettre \& Bernet, 1976). In non-allelic systems the genes encoding diffusible products are in the upper line $(V, C, G$ and $L)$ and those responsible for nondiffusible products (Bernet, 1965; Labarère et al., 1974) in the lower line.

To date, allelic incompatibility has been mainly studied in $N$. crassa. A mutation ( $t o l)$ has been identified that suppresses the PI resulting from the mating-type allele interaction (Newmeyer, 1970). This mutation did not help to interpret allelic PI as it has no phenotypic consequence in itself and no action on any allelic interaction other than that involving the mating-type alleles (Newmeyer, 1970; Perkins, 1988). There have been few studies of allelic PI in $P$. anserina. However, the $V$ gene (a single cistron) is involved in both allelic $\left(V / V_{1}\right)$ and non-allelic $(V / R)$ gene interaction (Fig. 1), which suggests that there is a connection between allelic and non-allelic PI. Furthermore, both allelic and non-allelic PI were suppressed by $\beta$-phenylpyruvic acid, a competitive protease inhibitor (Geratz, 1965) which acts strongly in vitro on the proteolytic activities responsible for nonallelic PI (Delettre et al., 1978).

Mutants of a gene, $\bmod D$, have been identified by their interactions with mutants of the $\bmod B$ gene involved in the expression of non-allelic PI. The modD mutations inhibit differentiation. Studies of $\bmod D$ mutations suggested that they affect exit from the stationary phase, a step which is a prerequisite for the transition from the vegetative to the developmental phase (Labarère \& Bernet, $1979 a$; Durrens et al., 1979; Durrens \& Bernet, 1982). Furthermore, comparative studies of wild-type and $\bmod D$ strains showed that exit from the stationary phase to initiate differentiation involves the action of proteolytic activities controlled by the modD gene. This has led therefore to the hypothesis of a possible connection between non-allelic PI and exit from the stationary phase (Labarère \& Bernet, 1979b). There was no conclusive evidence for this notion, as non-allelic incompatibility genes had not been demonstrated to be involved in stationary phase exit or to act on the $\bmod D$ gene.
The present work shows that there is a connection between the action of the modD gene and allelic PI, as modD mutations suppress the expression of allelic incompatibility genes. Furthermore, the action of the modD gene on development suggests that the genes of allelic incompatibility loci are involved in differentiation by controlling exit from the stationary phase.

\section{Methods}

Organism. Podospora anserina is fundamentally a heterothallic ascomycete that reproduces by means of binucleate ascospores which give the heterokaryotic $(+/-)$ self-fertile mycelia found in its natural environment (secondary homothallism: Ames, 1934). Due to the occasional production of uninucleate spores, it is possible to obtain the homokaryotic hermaphroditic self-sterile $(+$ or -$)$ mycelia needed for genetic studies and for barrage and PI analysis.

The developmental products of vegetative mycelium and the action of modD mutations. Vegetative mycelium mainly grows by the activity of apical cells. The hyphal cells, after they have been committed to stationary phase (Durrens \& Bernet, 1982), are the source of developmental products, which are : aerial hyphae (AH), distorted and slow-growing hyphae called secondary ramifications (SR) and, only when colony growth is stopped at the limit of the culture substrate, protoperithecia that support the female cycle up to spore production. Protoperithecia and perithecia develop outside the growth substrate. Mutations of the modD gene (Durrens \& Bernet, 1982) suppress the production of all three hyphal cell derivatives ( $h c d$ phenotype).

Incompatibility genes. Sixteen wild-type strains were studied. Five loci involved in allelic incompatibility were identified. Each locus was polymorphic for two active genes $\left(B_{1} / B_{2}, s / S \ldots Z_{1} / Z_{2}\right)$ with the exception of the $s$ locus, which has a neutral allele $s_{0}$ found only in one wild-type strain (Bernet, 1965, 1967). Non-allelic incompatibility genes are designated by capital letters $(C, D \ldots)$ when they are involved in lethal recombinant interactions $(C / D, R / V \ldots)$ and by lower-case letters when in non-lethal combinations $(c / d \ldots f / g \ldots r / v)$, irrespective of the wild-type strain from which they originated.

$\bmod D$ mutations. Three mutations of the $\bmod D$ gene have been described. mod $D-1$ was isolated from a strain of complex genotype which was lethal due to a mutation inhibiting modB gene expression (Labarère \& Bernet, $1979 a$ ). modD-2 and -3 were identified as suppressing a lethal modB mutation (Durrens et al., 1979). The modD mutations were tested for dominance or recessiveness in the context of their screening (autolysis suppression): $M o d D-1$ is recessive; $\bmod D-2$ and -3 are dominant. All $\bmod D$ mutations were outcrossed for the determination of their own phenotypic effects. All original modD mutations inhibit the production of hyphal cell derivatives and ascospore outgrowth (Table 1 ). The inhibitory action of the modD-I mutation on ascospore outgrowth and production of secondary ramifications (the only hyphal cell derivatives that develop inside the culture medium) is suppressed in media supplemented with $\beta$ phenylpyruvic acid (Labarère \& Bernet, 1979a, b), a competitive proteinase inhibitor (Geratz, 1965; Barnett, 1967).

Reversions of modD-2 and modD-3 mutations. The procedure for screening for revertants of the dominant modD mutants has been described (Durrens, 1982). Growth of autolytic strains of $C E \bmod D-2$ or -3 genotypes stops during development and most of cells lyse as a consequence of the $C / E$ interaction. In $C E$ strains, growing mutant sectors develop from viable cells that generally result from mutations of the $E$ gene ( $E / e$ mutations suppressing the lethal interaction with the $C$ 
Table 1. Ascospore outgrowth and the production of hyphal cell derivatives

\begin{tabular}{|c|c|c|c|c|c|c|}
\hline & \multirow[b]{3}{*}{$\begin{array}{l}\text { Dominance/ } \\
\text { recessiveness }\end{array}$} & \multirow{2}{*}{\multicolumn{2}{|c|}{ Ascospore outgrowth }} & \multicolumn{3}{|c|}{ Production of hyphal cell derivatives } \\
\hline & & & & \multirow[b]{2}{*}{$\begin{array}{l}\text { Aerial } \\
\text { organs }\end{array}$} & \multicolumn{2}{|c|}{ Secondary ramifications } \\
\hline & & Control & $\begin{array}{c}+\beta-\mathrm{PPA}^{*} \\
(0.03 \mathrm{M})\end{array}$ & & Control & $\begin{array}{c}+\beta \text {-PPA* } \\
(0.04 \mathrm{M})\end{array}$ \\
\hline $\bmod D^{+}$ & & + & - & + & + & - \\
\hline $\bmod D-1 \dagger$ & Recessive & $\begin{array}{c}- \\
\text { (ascospore } \\
\text { killed) }\end{array}$ & + & - & - & + \\
\hline $\begin{array}{l}\bmod D-2 \ddagger \\
\bmod D-3\end{array}$ & Dominant & $\begin{array}{c}+ \\
\text { (dormancy) }\end{array}$ & - & - & - & - \\
\hline
\end{tabular}

gene). Due to the inhibitory action of the modD mutations (inhibition of the growth renewal from stationary-phase cells), the $e$ mutant sectors from the $C E \bmod D$ strains also contain, in most cases $(80 \%)$, a reversion of the modD mutation. Phenotypically, the modD revertants are identified by the restoration of protoperithecium and aerial hyphae production ( $h c d^{+}$phenotype). Each of the three $\bmod D-2\left(-2_{1},-2_{2},-2_{3}\right)$ and the two modD-3 $\left(-3_{1},-3_{2}\right)$ revertants used in this work were crossed with the reference wild-type strain. The absence of strains of the hcd phenotype, among more than $200 \mathrm{fl}$ strains examined for each cross, indicated that the reverse mutations mapped in, or close to, the mod $D$ locus.

Strain genotypes. The modD mutations $(-1,-2,-3)$ were screened from the reference strain, which contains the active allelic incompatibility genes $B_{1}, Q_{1}, s, V$ and $Z_{1}$. For barrage and $P I$ analysis, the $\bmod D$ strains were confronted with a wild-type $\left(\bmod D^{+}\right)$strain differing from the reference strain by the presence of one of the antagonistic alleles, $B_{2}, Q_{2}, S, V_{1}$ or $Z_{2}$

Determination of PI by barrage production or cell lysis. Implants from the strains to be confronted were deposited on solid medium at a distance of $3 \mathrm{~cm}$, so that colony confluence occurred within 2 to $3 \mathrm{~d}$. PI manifests itself by the production of an unpigmented mycelium excrescence called 'barrage' (Rizet, 1953). Barrage is due to the growth renewal of the cells situated behind the lysed cells at the tips of hyphae (Beisson-Schecroun, 1962). modD mutations $(-1,-2,-3)$ suppress the production of a barrage when they are present in both matched strains by inhibition of the growth renewal of hyphal cells (Durrens \& Bernet, 1982). Accordingly, no barrage is produced by strains containing $\bmod D-1,-2$ or -3 mutations and microscopic examination in the confluence area of two such matched strains is thus necessary to detect PI. To facilitate this observation, the strains to be confronted were grown on a cellophane disk placed on culture medium to obtain a single monolayer of hyphae. Cells were examined less than $12 \mathrm{~h}$ after colony meeting. The PI reaction starts with the appearance of large vacuoles, continues with a violent agitation of newly formed cytoplasmic granules and terminates by protoplasm extrusion (Rizet \& Schecroun, 1959; Bernet, 1965). These abnormal features are specific to PI, as the neighbouring healthy cells of the same age have dense and homogeneous cytoplasmic contents. It is not possible to assess the times of individual anastomoses (between 2 and $10 \mathrm{~h}$ ) and thus to know whether the $\mathrm{PI}$ reaction is normal (cell destruction in 2-3 h), retarded or of weak intensity. When one of the matched strains is $\bmod D^{+}$and the other modD, PI is accompanied by the production of a barrage (mycelial excrescence by the mod $D^{+}$strain) and is therefore easily detected. A $C / E$ non-allelic incompatibility gene interaction, which is not suppressible by the modD mutation (Durrens et al., 1979), was used as the positive control for the barrage test.

\section{Results}

Effect of the modD mutations on the expression of the allelic incompatibility genes of the reference strain

The reference strain with the $B_{1} Q_{1} s V Z_{1}$ genotype contained the $\bmod D$ mutations. All three original $\bmod D$ mutants and five revertants from the two dominant $\bmod D$ mutants $(\bmod D-2,-3)$ were confronted for the production of a barrage with wild-type $\left(\bmod D^{+}\right)$strains differing from the reference strain by the presence of the active allelic incompatibility genes $B_{2}, Q_{2}, S, V_{1}$ or $Z_{2}$ (see Fig. 1). In the absence of the $\bmod D$ mutations all allelic interactions tested $\left(B_{1} / B_{2}, Q_{1} / Q_{2}, s / S, V / V_{1}\right.$, or $Z_{1} / Z_{2}$ ) will result in the production of a barrage morphologically similar to that produced by the nonallelic incompatibility gene interactions. The results, summarized in Table 2, show that there was no barrage in several of the strain confrontations involving allelic gene interactions. This contrasts with the non-allelic $C / E$ barrage used as a control for barrage production. The dominant mutations $\bmod D-2,-3$ were more active in barrage suppression than the recessive $\bmod D-1$ mutation. In some strain confrontations, barrage was expressed by a thin and discontinuous mycelial excrescence (attenuated barrage). The modD-2 mutation completely inhibited the barrage expressed by $B_{1}, Q_{1}, s$ and $Z_{1}$ and partially inhibited that which involved the $V$ gene.

The $\bmod D-1$ mutation apparently acted only on the $B_{1}$, $s$ and $V$ genes, and this resulted in the attenuation of the barrage expressed by these genes. Revertants from 
Table 2. Barrage production between the reference strain Ce $B_{1} Q_{1} s V Z_{1}$ containing a modD mutation and a wild-type strain $\left(\bmod D^{+}\right)$differing from the reference strain by the presence of the antagonistic allelic incompatibility gene $B_{2}, Q_{2}, S, V_{1}$ or $Z_{2}$ or the $E$ non-allelic incompatibility gene

+ , Barrage; a, barrage attenuated; - , barrage inhibited

\begin{tabular}{ccccccc}
\hline \hline & \multicolumn{7}{c}{$\bmod D^{+}$strain: } \\
\cline { 2 - 7 } $\begin{array}{cccccc}\bmod D \\
\text { mutation }\end{array}$ & $B_{2}$ & $Q_{2}$ & $S$ & $V_{1}$ & $Z_{2}$ & $(C / E$ interaction $)$ \\
\hline $\bmod D^{+}$ & + & + & + & + & + & + \\
$\bmod D-1$ & a & + & a & a & + & + \\
-2 & - & - & - & - & - & + \\
-3 & - & a & - & - & - & + \\
-21 & + & - & + & - & + & + \\
-22 & + & - & + & + & + & + \\
-23 & + & + & + & + & + & + \\
-31 & - & + & + & + & + & + \\
-32 & + & + & + & + & + & + \\
\hline \hline
\end{tabular}

$\bmod D-2,-3$ no longer suppressed barrages that were suppressed by the original mutants. It thus appears that reversion of modD towards normal production of hyphal cell derivatives $\left(\mathrm{Hcd}^{-}\right.$versus $\mathrm{Hcd}^{+}$phenotype) is accompanied by a concomitant restoration of barrage production.

Comparison of the effects of modD mutations on the expression of the two alleles of each allelic incompatibility locus

In the $\bmod D-1$ mutant and in $\bmod D-2_{1}$ and $-2_{2}$ revertants, the allelic incompatibility genes $B_{1}, Q_{1}, s, V$ or $Z_{1}$ of the reference strain were replaced by their antagonistic alleles $B_{2}, Q_{2}, S, V_{1}$ or $Z_{2}$, respectively, by outcrossing. The five new recombinant genotypes for the $\bmod D$ mutants were thus $B_{2} Q_{1} s V Z_{1} \ldots$ to $B_{1} Q_{1} s V Z_{2}$. Each recombinant strain was matched to the wild-type $\left(\bmod D^{+}\right)$reference strain $\left(B_{1} Q_{1} s \quad V \quad Z_{1}\right)$. Barrage production in each of these confrontations (for instance $\bmod D^{+} B_{1} / \bmod D B_{2}$ ) was compared (Table 3 ) with that previously found $\left(\bmod D B_{1} / \bmod D^{+} B_{2}\right)$ with the same allelic incompatibility gene interaction (Table 2). The action of the modD mutations was not locus specific but was allele specific: the $\bmod D-2$, mutation inhibited expression of the $S$ and $V$ genes in the barrage production and not that of the corresponding alleles, $s$ and $V_{1}$.

\section{Effect of modD mutations on allelic incompatibility}

To assess whether the absence of a barrage in $\bmod D /$ mod $D^{+}$strain confrontations is due to a suppression of PI (and not to the inhibition of the barrage itself) cells were examined in the confluence area of strains containing identical $\bmod D$ mutations. In the absence of the $\bmod D$
Table 3. Comparisons of the effects of three modD mutations on the expression in barrage production of the two alleles of each allelic incompatibility locus

+ , Barrage; a, barrage attenuated; - , barrage inhibited. The effects of the $\bmod D$ mutations on $B_{1}, Q_{1}, s, V$ and $Z_{1}$ alleles come from the results of Table 2 .

\begin{tabular}{lccccc}
\hline \hline & \multicolumn{5}{c}{ Allele pair: } \\
\cline { 2 - 6 } $\bmod D$ & $B_{1}: B_{2}$ & $Q_{1}: Q_{2}$ & $s: S$ & $V: V_{1}$ & $Z_{1}: Z_{2}$ \\
\hline $\bmod D-1$ & $\mathrm{a}: \mathrm{a}$ & $+:+$ & $\mathrm{a}: \mathrm{a}$ & $\mathrm{a}: \mathrm{a}$ & $+:+$ \\
$\bmod D-21$ & $+:+$ & $-:-$ & $+:-$ & $-:+$ & $+:+$ \\
$\bmod D-22$ & $+:+$ & $-:-$ & $+:+$ & $+: \mathrm{a}$ & $+:+$ \\
\hline \hline
\end{tabular}

Table 4. Presence of lysing and disintegrated cells in the confluence area of matched strains containing identical modD mutations and differing in a pair of allelic incompatibility genes

+ , Lysed cells; -, no lysed cells.

\begin{tabular}{lccccc}
\hline \hline \multirow{2}{*}{ Mutation } & \multicolumn{5}{c}{ Allelic incompatibility gene interaction: } \\
\cline { 2 - 6 } & $B_{1} / B_{2}$ & $Q_{1} / Q_{2}$ & $s / S$ & $V / V_{1}$ & $Z_{1} / Z_{2}$ \\
\hline $\bmod D-1$ & - & + & - & - & + \\
$\bmod D-2$ & - & - & - & + & - \\
$\bmod D-21$ & + & - & - & - & + \\
\hline \hline
\end{tabular}

mutations, it is known (Beisson-Schecroun, 1962; Bernet, 1965) that the confluence area of strains carrying antagonistic incompatibility genes (allelic or non-allelic) contains lysing or disintegrated cells. These dead cells are associated with anastomoses between hyphae from the opposite strains. This investigation (results in Table 4) showed that there were no dead cells in most of the 
confluence areas despite the production of anastomoses. This showed that the suppression of allelic barrages in $\bmod D^{+} / \bmod D$ strain confrontations (Tables 2 and 3 ) was due to inhibition of PI. Furthermore, suppression of the expression of a single allele was sufficient to inhibit PI. The modD-2l mutation inhibited $S / s$ and $V / V_{1}$ allelic PI (Table 4) due to its action on the $S$ and $V$ alleles alone (Table 3). $B_{1} / B_{2}, S / s$ and $V / V_{1}$ allelic PI were suppressed by the modD-1 mutation. This suggests that the presence of an attenuated barrage in the $\bmod D-1 / \bmod D^{+}$strain confrontations involving these interactions (Table 2) is due to the recessiveness of the mutation: in the $\bmod D / \bmod D^{+}$heterokaryotic cells that result from the fusion of $\bmod D-1$ and $\bmod D^{+}$hyphae, the presence of the $\bmod D^{+}$gene is thought to restore, at least partially, the action of the allelic incompatibility gene carried by the $\bmod D-1$ strain.

\section{Discussion}

Allelic PI is presumed to result from the interactions of proteins encoded by corresponding alleles (Rizet \& Schecroun, 1959; Wilson et al., 1961; Turcq et al., 1991). This work shows that the modD gene product is involved in allelic PI. Indeed (Table 2), the dominant modD-2, -3 mutations suppress barrage irrespective of the allelic gene interactions $\left(B_{1} / B_{2}\right.$ to $\left.Z_{1} / Z_{2}\right)$. This suppression thus establishes a significant difference between allelic and non-allelic PI (Durrens et al., 1979; Durrens, 1982) since barrage production due to non-allelic gene interactions is not inhibited by the modD mutations. The general inhibition of allelic PI by the dominant mutations $\bmod D-2$ and $\bmod D-3$ suggests that the $\bmod D$ gene exerts a negative control on the phenomenon. Other modD mutations ( $\bmod D-1,-21-22$ or -31$)$ suppress only a part of the allelic barrages and the allelic interactions inhibited vary according to the modD mutations (Table 2). This leads to the presumption that the modD gene product does not act downstream of those of the allelic incompatibility genes in the general allelic PI pathway and is a common factor of the trigger mechanism of allelic PI. Allelic PI appears therefore to involve the action of the $\bmod D$ gene presumptively as the result of the complementary actions of the alleles of each incompatibility locus. Previous work showed that allelic PI (like non-allelic PI) is due to the expression of particular proteases (Delettre et al., 1978). It may be deduced, from the suppression of allelic PI by $\bmod D$ mutations, that the modD gene is involved in the control (probably negative) of these proteases.

Previous work indicated that the modD gene controls differentiation presumptively by affecting exit from the stationary phase (Durrens \& Bernet, 1982). It was also shown that exit from the stationary phase (and ascospore germination) requires the action of proteolytic activities, the production of which depends on the modD gene (Labarère \& Bernet, 1979a). Furthermore, it has been deduced, from the study of non-allelic PI $(C / D, F / G \ldots$ $R / V$ interactions), that the $\bmod B$ gene is responsible for a general repression of the proteolytic activities (and their associated catabolite activities) specific to non-allelic PI (Bégueret \& Bernet, 1973; Boucherie et al., 1976a). Consistent with this notion, a recessive mutation of $\bmod B$ results in an autolytic mutant (viable and growing only on a medium supplemented with $\beta$-phenylpyruvic acid) in which the protein synthesis specific to non-allelic PI (almost 50 polypeptides) is constitutive (Boucherie et al., 1976b, 1981; Boucherie, 1983). modD mutations were screened either by action on a $\bmod B$ mutation $(\bmod D-2$, $-3)$ or the suppression of a mutation inhibiting $\bmod B$ (modD-1). This indicates therefore a connection between the actions of $\bmod D$ and $\bmod B$ genes (Labarère \& Bernet, 1979a; Durrens et al., 1979). The proteolytic activities associated with the action of the $\bmod D$ gene in stationary phase exit (and ascospore outgrowth) and in allelic incompatibility (the present work) are presumably those that are normally repressed by the $\bmod B$ gene. The $\bmod B$ gene therefore appears to be a common repressor for the lytic activities expressed by allelic and non-allelic PI. Accordingly, there is probably no difference in the biochemistry of allelic and non-allelic PI other than the trigger mechanism (allelic or non-allelic interaction).

The demonstration that $\bmod A \bmod B$ double mutations (which together suppress non-allelic PI) in hibit cell death has led to the recognition of a connection between nonallelic PI and cell death (Bernet, 1991). Furthermore, it was shown that the genes of the $c-v$ non-allelic incompatibility loci are also involved in the control of cell death via the additive, redundant and minor effects of the gene interactions $c / e \ldots f / g \ldots r / v$ (homologous to the $C / E \ldots F / G \ldots R / V$ lethal autolytic interactions). It has therefore been presumed that non-allelic PI is an artefact due to the dysregulation of the degradative activities (especially the proteases) evolved to transform the stationary-phase cells of fertile cultures into a source of nutrients for developing fruiting bodies (Bernet, 1992).

The specific suppression of allelic PI by $\bmod D$ mutations (this work) indicates a connection between allelic PI and exit from the stationary phase to promote differentation. There is no demonstration to date that the genes of the allelic incompatibility loci are involved in the control of stationary phase exit via their action on the $\bmod D$ gene. However, indirect evidence for such involvement comes from the comparison of the original modD -2, -3 mutants to their revertants (Table 2). Indeed, it is a general observation that normal and subnormal expression of $\bmod D$ alleles in differentiation correlates 


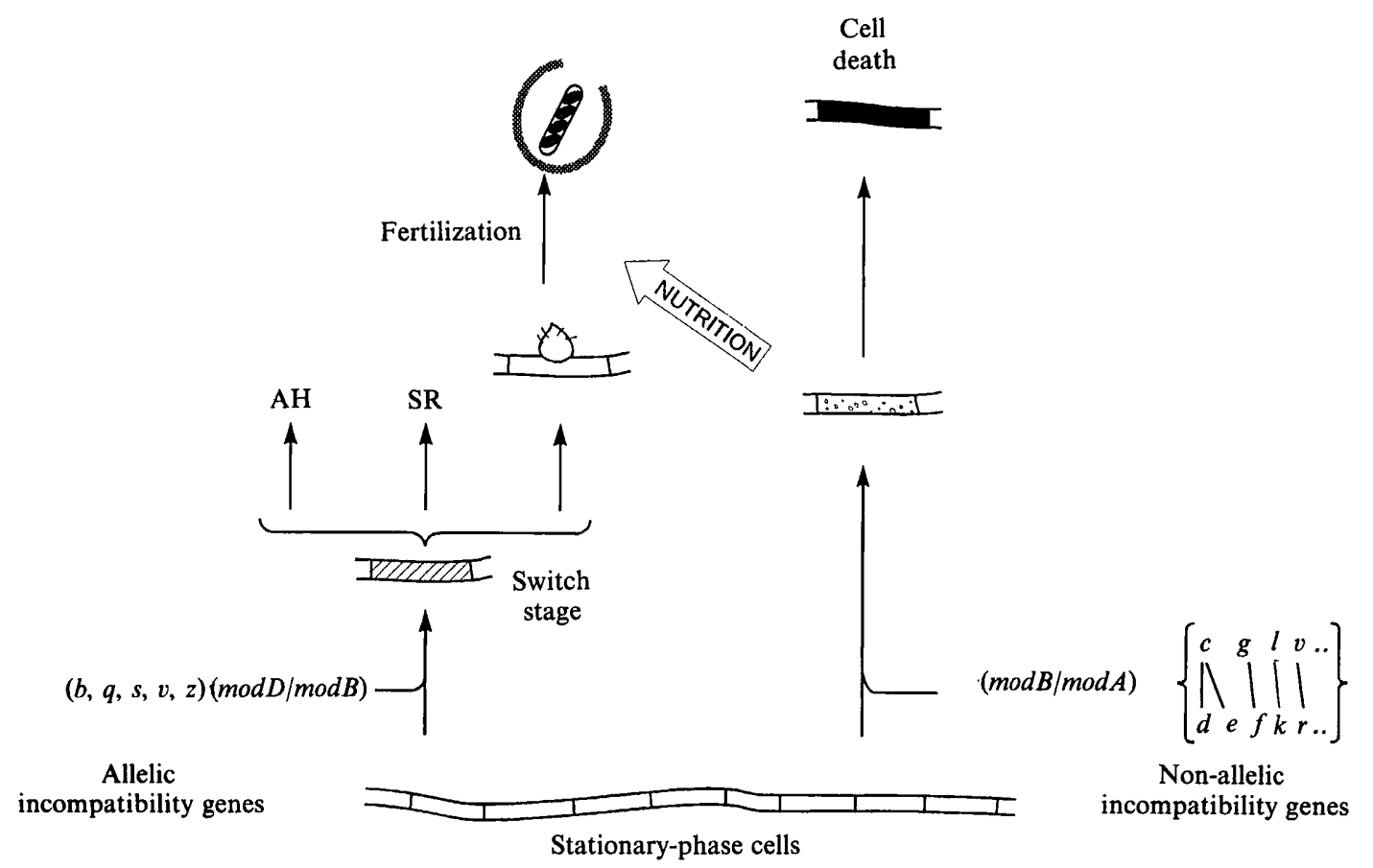

Fig. 2. Hypothetical roles of the allelic and non-allelic incompatibility genes in the developmental cycle of $P$. anserina (for explanations see text). AH, aerial hyphae; SR, secondary ramifications.

with normal and subnormal expression of allelic PI. This supports the idea that allelic PI may be deviant expression of the function required to exit from the stationary phase. This suggests therefore that the genes of the allelic incompatibility loci might also be involved in this function. Since each allelic incompatibility gene can interact with the modD gene, it is possible that these genes exert redundant actions on the $\bmod D$ gene responsible for the control of the proteolytic activities required to disrupt stationary phase. Gene redundancy is assumed to be a general phenomenon in the control of complex developmental processes (Nasmyth, 1990).

A possible model for the postulated action of the allelic incompatibility genes of $P$. anserina is given by the genetics of the G1-cyclins of Saccharomyces cerevisiae (Reed, 1991). The G1-cyclin genes exert redundant functions, as the action of only one gene is sufficient to induce transition to the $S$ phase. Gene redundancy is used to link exit from the G1 phase to several parameters of cell physiology (nutritional conditions, cell cycle phase, cell size, etc.). It is possible that the allelic incompatibility genes of $P$. anserina participate in the control of a phenomenon developmentally controlled to occur during stationary phase and programmed to affect the few vegetative cells that are transformed into the stem cells used for differentiation. The hypothetical model for the action of the allelic incompatibility genes in the developmental cycle of $P$. anserina is summarized in Fig. 2, together with an overview of a preceding hypothesis on the action of the non-allelic incompatibility genes. Some features of the postulated actions of allelic and non-allelic incompatibility genes may be noted. (1) Incompatibility genes, whether allelic or nonallelic, control various functions in stationary-phase cells: exit from the stationary phase, entry into a developmental pathway (allelic incompatibility genes) or cell death (non-allelic incompatibility genes). In other words $P$. anserina PI (allelic or non-allelic) may be considered as the deviant expression of two stationaryphase functions that are mutually exclusive: differentiation and vegetative cell death. (2) Incompatibility genes are assumed to exert redundant regulatory functions: redundancy in the action of individual genes (allelic incompatibility genes) or redundancy of specific gene interactions leading to two complementary multigene systems (non-allelic incompatibility genes). (3) Allelic and non-allelic incompatibility genes act upstream from the regulatory genes $\bmod A$ and $\bmod B$ (for non-allelic incompatibility genes), $\bmod D$ and $\bmod B$ (allelic incompatibility genes) that are responsible for the transcriptional shifts associated with PI expression. Experiments are in progress to establish whether there is a direct link between $\bmod D$ and the allelic incompatibility genes outside their common actions on allelic PI. Furthermore, the $\bmod B$ and $\bmod D$ genes have been cloned and their nucleotide sequences will shortly be determined (J. Bégueret, personal communication).

In $P$. anserina, production of interfertility barriers and 
f1 lethal strains are the result of the actions of allelic and non-allelic incompatibility genes alone (Bernet, 1965, 1967). PI genes are thus potent factors that may restrict genetic exchange in the wild. This has led to the hypothesis that incompatibility genes have evolved to produce isolating mechanisms used to counterbalance the outbreeding action of the mating-type locus (Esser, 1971; Esser \& Blaich, 1973). This presumptive function of the PI genes appears gratuitous. Indeed, it is known that wild-type isolates of $P$. anserina in their natural environment are scattered and self-fertile (Bernet et al., 1960). Furthermore, potential intercrossing is limited, as $P$. anserina microconidia (the male gametes) are not airborne (Bernet, 1965). In Esser's hypothesis (1971), PI is thus suspected to have evolved for the control of functions that are already fulfilled by other genetic systems, in particular the secondary homothallism due to the normal production of $+1-$ heterokaryotic ascospores. However, the proposition that PI is an artefact leads to an apparent paradox. The incompatibility genes have redundant and minor (and consequently nearly undetectable) effects in their presumptive genuine functions (cell death or stationary-phase exit) and major effects in their deviant expressions (non-allelic or allelic PI) as the results of single mutations.

\section{References}

AMEs, L. M. (1934). Hermaphroditism involving self-sterility and cross-fertility in the ascomycete Pleurage anserina. Mycologia 26, 392-414.

BARNETT, A. J. (1967). Lysosomal acid proteinase of rat liver. Biochemical Journal 104, 601-608.

BÉgueret, J. \& Bernet, J. (1973). Proteolytic enzymes and protoplasmic incompatibility in the fungus Podospora anserina. Nature New Biology 243, 94-98.

BEISSON-SCHECROUN, J. (1962). Incompatibilité cellulaire et interactions nucléocytoplasmiques dans les phénomènes de barrage chez le Podospora anserina. Annales de Génétique 4, 1-50.

BERNET, J. (1965). Mode d'action des gènes de barrage et relation entre l'incompatibilité cellulaire et l'incompatibilité sexuelle chez le Podospora anserina. Annales des Sciences Naturelles, Botanique 6, 611768.

Bernet, J. (1967). Systèmes d'incompatibilité chez le Podospora anserina. Comptes Rendus de l'Académie des Sciences, D 265, 15361539.

Bernet, J. (1991). Aerial organs and cell death in Podospora anserina mutants: relationship with protoplasmic incompatibility. Experimental Mycology 15, 215-222.

Bernet, J. (1992). In Podospora anserina, protoplasmic incompatibility genes are involved in cell death control via multiple gene interactions. Heredity 68, 79-87.

Bernet, J., Esser, K., Marcou, D. \& Schecroun, J. (1990). Sur la structure génétique de l'espèce Podospora anserina et sur l'intêret de cette structure pour certaines recherches de génétique. Comptes Rendus de l'Academie des Sciences 250, 2053-2055

Boucherie, H. (1983). Protoplasmic incompatibility and the genetic control of stable messenger RNAs. Biochemical Genetics 21, 287-297.

BOUCHERIE, H. \& BERNET, J. (1974). Protoplasmic incompatibility and female organ formation in Podospora anserina: properties of mutations abolishing both processes. Molecular and General Genetics 135, 163-174.
Boucherie, H. \& Bernet, J. (1980). Protoplasmic incompatibility in Podospora anserina: a possible function for incompatibility genes. Genetics 96, 399-411.

BouCherie, H., Bégueret, J. \& Bernet, J. (1976a). The molecular mechanism of protoplasmic incompatibility and its relationship to the formation of protoperithecia in the fungus Podospora anserina. Journal of General Microbiology 92, 59-66.

Boucherie, H., Delettre, Y. M. \& Bernet, J. (1976b). A constitutive mutation in a posttranscriptional regulatory gene for a phenoloxidase and proteases in Podospora anserina. Biochemical Genetics 14, 857-868.

Boucherie, H., Dupont, C. H. \& Bernet, J. (1981). Polypeptide synthesis during protoplasmic incompatibility in the fungus Podospora anserina. Biochimica et Biophysica Acta 653, 18-26.

CATEN, C. E. (1972). Vegetative incompatibility and cytoplasmic infection in fungi. Journal of General Microbiology 72, 221-229.

DeleTtRE, Y. M. \& BERNET, J. (1976). Regulation of proteolytic enzymes in Podospora anserina: selection and properties of self-lysis mutant strains. Molecular and General Genetics 144, 191-197.

Delettre, Y. M., Boucherie, H. \& Bernet, J. (1978). Protoplasmic incompatibility and cell lysis in Podospora anserina: effect of $\beta$ phenyl pyruvic acid. Biochemie und Physiologie der Pflanzen 172, 27-34.

Durrens, P. (1982). Podospora mutant defective in glucose-dependent growth control. Journal of Bacteriology 154, 702-707.

Durrens, P. \& Bernet, J. (1982). Podospora anserina mutations inhibiting several developmental alternatives and growth renewal. Current Genetics 5, 181-185.

Durrens, P., Laigret, F., Labarère, J. \& Bernet, J. (1979). A Podospora mutant defective in protoperithecium formation, ascospore germination and cell regeneration. Journal of Bacteriology 140, 835-842.

ESSER, K. (1971). Breeding systems in fungi and their significance for genetic recombination. Molecular and General Genetics 110, 86-100.

EsSER, K. \& Blaich, R. (1973). Heterogenic incompatibility in plants and animals. Advances in Genetics 17, 105-152.

GARNJOBST, L. \& WILSON, J. F. (1956). Heterokaryosis and protoplasmic incompatibility in Neurospora crassa. Proceedings of the National Academy of Sciences of the United States of America 42, 613-618.

GeRATZ, J. D. (1965). $\alpha$-Keto analogs of amino acids as inhibitors of chymotrypsin, carboxypeptidase A and pepsin. Archives of Biochemistry and Biophysics 111, 133-144.

Hartl, D. R., Dempster, E. R. \& Brown, S. W. (1975). Adaptative significance of vegetative incompatibility in Neurospora crassa. Genetics 81, 553-559.

LABARÈRE, J. \& BERNET, J. (1979a). A pleiotropic mutation affecting protoperithecium formation and ascospore growth. Journal of General Microbiology 113, 19-27.

Labarère, J. \& Bernet, J. (1979 $b$ ). Protoplasmic incompatibility in Podospora anserina: a possible role for its associated proteolytic activity. Genetics 93, 525-537.

LABARÈRE, J., BÉGNERET, J. \& BERNET, J. (1974). Incompatibility in Podospora anserina: comparative properties of the antagonistic cytoplasmic factors of a non allelic system. Journal of Bacteriology 120, 854-860.

MYLYK, O. M. (1976). Heteromorphism for heterokaryon incompatibility in natural populations of Neurospora crassa. Genetics 83, 275284.

NASMYTH, K. A. (1990). Far-reaching discoveries about the regulation of start. Cell 63, 1117-1120.

NEWMEYER, D. (1970). A suppressor of the heterokaryon-incompatibility associated with mating type in Neurospora crassa. Canadian Journal of Genetics and Cytology 12, 914-926.

Perkins, D. D. (1988). Main features of vegetative incompatibility in Neurospora. Fungal Genetics Newsletter 35, 44-46.

Perkins, D. D., Radford, A., Newmeyer, D. \& BJörkman, M. (1982). Chromosome loci of Neurospora crassa. Microbiological Reviews 46, 426-570.

REED, S. I. (1991). G1-specific cyclins: in search of a S phasepromoting factor. Trends in Genetics 7, 95-99. 
RizeT, G. (1953). Sur la multiplicité des mécanismes génétiques conduisant à des barrages chez $P$. anserina. Comptes Rendus de l'Académie des Sciences 237, 666-669.

Rizet, G. \& Esser, K. (1953). Sur les phénomènes d'incompatibilité entre souches d'origines différentes chez Podospora anserina. Comptes Rendus de l'Académie des Sciences 237, 760-761.

RizeT, G. \& SCHECROUN, J. (1959). Sur les facteurs associés au couple de gènes $S$-s chez le Podospora anserina. Comptes Rendus de l'Académie des Sciences 249, 2392-2394.
TurcQ, B., Deleu, C., Denayrolles, M. \& Bégueret, J. (1991). Two allelic genes responsible for vegetative incompatibility in the fungus Podospora anserina are not essential for cell viability. Molecular and General Genetics 228, 265-269.

Wilson, J. F., Garnjobst, L. \& Tatum, E. L. (1961). Heterokaryon incompatibility in Neurospora crassa: micro-injection studies. American Journal of Botany 48, 299-305. 